\title{
Anti-contactin-1 Antibodies Affect Surface Expression and Sodium Currents in Dorsal Root Ganglia
}

Julia Grüner, MSc, Helena Stengel, MD, Christian Werner, PhD, Luise Appeltshauser, MD, MSc, Claudia Sommer, MD, Carmen Villmann, PhD, * and Kathrin Doppler, MD*

Neurol Neuroimmunol Neuroinflamm 2021;8:e1056. doi:10.1212/NXI.0000000000001056

\section{Abstract}

\section{Background and Objectives}

As autoantibodies to contactin-1 from patients with chronic inflammatory demyelinating polyradiculoneuropathy not only bind to the paranodes where they are supposed to cause conduction failure but also bind to other neuronal cell types, we aimed to investigate the effect of anticontactin-1 autoantibodies on contactin-1 surface expression in cerebellar granule neurons, dorsal root ganglion neurons, and contactin-1-transfected human embryonic kidney 293 cells.

\section{Methods}

Immunocytochemistry including structured illumination microscopy and immunoblotting was used to determine expression levels of contactin-1 and/or sodium channels after long-term exposure to autoantibodies from 3 seropositive patients. For functional analysis of sodium channels, whole-cell recordings of sodium currents were performed on dorsal root ganglion neurons incubated with anti-contactin-1 autoantibodies.

\section{Results}

We found a reduction in contactin-1 expression levels on dorsal root ganglion neurons, cerebellar granule neurons, and contactin-1-transfected human embryonic kidney 293 cells and decreased dorsal root ganglion sodium currents after long-term exposure to anti-contactin-1 autoantibodies. Sodium channel density did not decrease.

\section{Discussion}

Our results demonstrate a direct effect of anti-contactin-1 autoantibodies on the surface expression of contactin- 1 and sodium currents in dorsal root ganglion neurons. This may be the pathophysiologic correlate of sensory ataxia reported in these patients.
Correspondence

Dr. Doppler

doppler_k@ukw.de

*These authors contributed equally to this work.

From the Department of Neurology (J.G., H.S., L.A., C.S., K.D.), University Hospital Würzburg, Germany; Department of Biotechnology and Biophysics (C.W.), Julius-MaximiliansUniversity of Würzburg; and Institute of Clinical Neurobiology (C.V.), University Hospital, Julius-Maximilians-University of Würzburg, Germany. 


\section{Glossary}

CGN = cerebellar granular neuron; CNTN1 $=$ contactin-1; DRG $=$ dorsal root ganglia; $\mathbf{H C}=$ healthy control; LDH = lactate dehydrogenase; SIM = structured illumination microscopy; $2 \mathrm{R}=2$-day recovery phase.

Anti-contactin-1 (CNTN1)-associated autoimmune neuropathy was first described in $2013^{1}$ and belongs to the meanwhile well-established category of neuropathies with antiparanodal autoantibodies. ${ }^{2-4}$ Because of the supposed site of attack, they are often referred to as "paranodopathies." 3,5 Paranodal autoantibodies mainly belong to the IgG4 subclass that does neither activate complement nor induce internalization of surface proteins. ${ }^{6-9}$ Pathogenicity is hypothesized to be caused by blocking of protein-protein interactions. Recent studies focused on pathogenic mechanisms at the paranodes and gave evidence of an axoglial detachment. ${ }^{10-13}$ Passive transfer experiments demonstrated impaired motor nerve conduction, motor deficits, and loss of paranodal proteins, the latter only after chronic antiCNTN1 exposure. ${ }^{14,15}$ CNTN1 is not restricted to the paranodes but is also found at dorsal root ganglia (DRG) neurons and cerebellar granule neurons (CGNs), ${ }^{16,17}$ where it regulates sodium current densities predominantly in small nociceptive DRG neurons. ${ }^{18,19}$ The effect of anti-CNTN1 autoantibodies on DRG neurons has never been studied, although it has been hypothesized that sensory ataxia, another major clinical symptom of anti-CNTN1-positive patients, may be induced by binding to DRG neurons. ${ }^{20}$ Here, we investigated the effect of anti-CNTN1 autoantibodies on CGNs and DRG neurons, hypothesizing that the paranodes are not the only site of attack in anti-CNTN1-associated polyneuropathies.

\section{Methods}

\section{Patients}

Sera of 3 patients with anti-CNTN1 autoantibodies and 3 healthy individuals (HC) were used for the experiments. All 3 patients were described previously. ${ }^{13}$ As patients' material is limited and pat 2 and pat 3 had a similar IgG subclass composition, the studies on the surface expression of CNTN1 were only conducted with pat1 (mainly IgG3) and pat3 (mainly IgG4).

\section{Standard Protocol Approvals, Registrations, and Patient Consents}

All participants gave written informed consent to take part in the study. The study was approved by the Ethics Committee of the University of Würzburg.

\section{Cell Culture Experiments}

Human embryonic kidney cells (HEK293, ATCCCRL-1573, Wesel, Germany) were grown and transfected with CNTN1 Glyceraldehyde 3-phosphate dehydrogenase as previously described. ${ }^{13}$

Primary culture of DRG neurons and CGNs was established by using adult mice or mouse embryos from CD-1 and C57BL/6 mice (eAppendix 1, links.lww.com/NXI/A536).

\section{Immunocytochemistry}

Binding assays of anti-CNTN1 autoantibodies were performed with CNTN1-transfected HEK293 cells, adult and embryonal DRG neurons, or CGNs. In brief, HEK293 cells and adult DRG neurons were blocked, incubated with primary antibodies, fixed, and incubated with fluorescent secondary antibodies. Embryonal DRG neurons and CGNs were first fixed, then blocked and incubated with primary and secondary antibodies. Immunocytochemistry of pan-neurofascin, $\beta$-III tubulin, and pan-sodium channel was performed on CGNs or adult DRG neurons after incubation with patients' material or serum of a healthy control $(\mathrm{HC})$. For detailed methods, see eAppendix 1, links.lww.com/NXI/A536.

\section{Cytotoxicity Assay}

Cytotoxicity of CNTN1 autoantibodies to CGNs was determined by measuring lactate dehydrogenase (LDH) release using the Cytotoxicity Detection Kit ${ }^{\mathrm{PLUS}}$ (LDH) (Roche) according to the manufacturer's instructions. CGNs were plated on 96-well plates. $\mathrm{LDH}$ release of untreated cells served as low control, whereas LDH release of cells treated with $2 \%$ Triton X-100 served as high control. Relative cytotoxicity of neurons incubated with serum of a HC, pat1, or pat3 (1:100) was calculated as follows:

$$
\text { relative cytotoxicity }(\%)=\frac{\text { test sample }- \text { low control }}{\text { high control }- \text { low control }} \times 100 \text { eq. } 1
$$

\section{Whole-Cell Lysate Preparation of Cerebellar Granule Neurons and Immunoblotting}

CGNs were incubated with serum of pat1, pat 3 , or $\mathrm{HC}$ for 2 or 4 days. Recovery (2-day recovery phase $[2 R]$ ) was studied by 2-day incubation of serum of pat 1 or pat 3 followed by incubation with serum of a $\mathrm{HC}$ for 2 days. Whole-cell lysates were prepared using the CytoBuster Protein Extraction Reagent (Merck Millipore, Billerica, MA). Separation of proteins was performed on $12 \%$ SDS-PAGE gels, and Western blots were stained with anti-CNTN1 (1:1,000; R\&D Systems) and antiGlyceraldehyde 3-phosphate dehydrogenase (1:2,000; Thermo Fisher Scientific) and appropriate secondary antibodies.

\section{Generation of Fab and $F\left(a b^{\prime}\right)_{2}$ Fragments From Human IgG and Validation by Anti-CNTN1 ELISA} Purified whole IgG from plasma exchange material of pat 1 , pat3, and a seronegative control patient had been obtained previously $^{21}$ and was used to generate and purify Fab and $\mathrm{F}\left(\mathrm{ab}^{\prime}\right)_{2}$ fragments with Pierce $\mathrm{F}\left(\mathrm{ab}^{\prime}\right)_{2}$ and Fab Preparation Kit (\#44988, \#44985, Thermo Fisher Scientific), following the instructions of the manufacturer. Briefly, spin columns containing immobilized pepsin and papain preparations were incubated for either 6 hours (papain) or 7.5 hours (pepsin) with 
desalted IgG samples diluted at $8 \mathrm{mg} / \mathrm{mL}$ in digestion buffer. Fab or $\mathrm{F}\left(\mathrm{ab}^{\prime}\right)_{2}$ fragments and remnants containing $\mathrm{Fc}$ fragments or undigested IgG were collected separately using Protein A Spin Columns and IgG Elution Buffer. Efficacy of purification was validated by anti-CNTN1 ELISA as previously described, using serum diluted 1:100, purified whole $\operatorname{IgG}, \operatorname{IgG} F a b, \operatorname{IgGF}\left(\mathrm{ab}^{\prime}\right)_{2}$, and eluted remnant containing $\mathrm{Fc}$ fragments and undigested $\operatorname{IgG} 1$ : 5-1:50 as primary antibodies and horseradish peroxidaseconjugated anti-human IgG (1:10,000, Dako DakoCytomation, Glostrup, Denmark) and mouse anti-human IgG Fab (1:10,000, GenScript Biotech, Piscataway, NJ) as secondary antibodies. Dilution factors for IgG Fab and $\mathrm{F}\left(\mathrm{ab}^{\prime}\right)_{2}$ resulting in an $\mathrm{OD}$ equally high to serum were used for DRG preincubation to ensure comparability of the results (eAppendix 1, links.lww.com/NXI/A536).

\section{Immunocytochemistry After Fab and $\mathrm{F}\left(\mathrm{ab} \mathrm{b}^{\prime}\right)_{2}$ Binding}

Adult DRG neurons were incubated with patient serum, $\mathrm{HC}$, or generated $\mathrm{Fab}$ and $\mathrm{F}\left(\mathrm{ab}^{\prime}\right)_{2}$ fragments for 2 days. After 24 hours, fresh patient serum or Fab or $\mathrm{F}\left(\mathrm{ab}^{\prime}\right)_{2}$ fragments were added. Untreated cells were used as additional control. After 48 hours, cells were fixed in $4 \%$ paraformaldehyde and blocked with $10 \%$ $\mathrm{BSA} / \mathrm{PBS}$ for 20 minutes followed by 5 minutes in 1\% BSA/PBS. Incubation with CNTN1 antibody (1:500) was performed at $4^{\circ} \mathrm{C}$ overnight. Secondary antibody incubations (goat anti-human IgG-Cy3, donkey anti-goat IgG-Cy3, and mouse anti-human Fab$\mathrm{Cy} 3$, all used 1:500) were performed for 1 hour at $21^{\circ} \mathrm{C}$. 4,6diamidino-2-phenylindole was used in a 1:10,000 dilution to mark the nucleus. Cover slips were mounted with Mowiol.

\section{Biotinylation of Cell Surface Protein and Immunoblotting}

Twelve hours after transfection, HEK293 cells were incubated under the same conditions ( 2 days, 4 days, and $2 \mathrm{R}$ ) with either $\mathrm{HC}$ sera or pat sera (1:500 in medium).

Cell surface biotinylation experiments were performed from transfected HEK293 cells as described previously. ${ }^{22}$ Samples were loaded on $11 \%$ SDS-PAGE gels. Western blots were labeled with anti-CNTN1 antibody (1:250; R\&D Systems), anti- $\beta$-actin antibody (1:5,000; Biozol, Eching, Germany), or anti-ATPase antibody (1:10,000; Abcam, Cambridge, UK) and appropriate secondary antibodies.

\section{Structured Illumination Microscopy}

Recordings of immunostained DRG neurons were performed on a structured illumination microscopy (SIM) Zeiss ELYRA S.1 system with a Plan-Apochromat 63x/1.40 oil immersion objective by applying structured illumination using 5 rotational and 5 phase variations. The image was reconstructed in ZEN software (ZEN 2.3, Carl Zeiss Microscopy GmbH, Jena, Germany), and the quality was validated with the ImageJ plugin SIMcheck. ${ }^{23}$ Channel alignment was performed in ZEN to correct chromatic aberration. In FIJI, ${ }^{24}$ brightness and contrast of exemplary SIM images were adjusted linearly and using identical values for all experimental groups. Colocalization analysis was performed in Imaris (Version 8.4.1, Bitplane AG, Zurich, Switzerland) using the colocalization package. Thresholding of colocalized signals was performed applying fixed parameters for all treatment groups, and Pearson correlation coefficients were calculated. Signal intensities of CNTN1 and pan- $\mathrm{Na}_{\mathrm{V}}$ were extracted over CNTN1 region of interest (ROI) in Imaris. CNTN1 ROIs were created by thresholding CNTN1 signal using fixed parameters for all group comparisons. Plot profiles were generated using FIJI's "Plot profile" tool and visualized using Origin (OriginPro, Version 2020; OriginLab Corporation, Northampton, MA).

\section{Electrophysiologic Whole-Cell Recordings}

Whole-cell recordings of DRG sodium currents were performed after specific incubation times $(1,2,24,48$, or 72 hours) with serum of HCs, pat1, pat2, or pat 3 material. Current signals from voltageclamp recordings of DRG neurons with depolarization steps of 10 $\mathrm{mV}$ between -80 and $+60 \mathrm{mV}$ were amplified using an EPC-10 amplifier (HEKA, Lambrecht, Germany). The holding potential was $-70 \mathrm{mV}$. All experiments were performed at $20^{\circ} \mathrm{C}$. Recording pipettes were produced from borosilicate glass capillaries with resistances of about $5 \mathrm{M} \Omega$. The internal solution contained $140 \mathrm{mM}$ CsF, $1 \mathrm{mM}$ ethylene glycol tetraacetic acid, $10 \mathrm{mM} \mathrm{NaCl}$, and $10 \mathrm{mM}$ HEPES with a $\mathrm{pH}$ adjusted to 7.3 and an osmotic concentration of $310 \mathrm{mOsm} / \mathrm{L}$. The external solution consisted of $70 \mathrm{mM} \mathrm{NaCl}, 70 \mathrm{mM}$ choline chloride, $3 \mathrm{mM} \mathrm{KCl}, 1 \mathrm{mM} \mathrm{MgCl}_{2}$, $1 \mathrm{mM} \mathrm{CaCl}_{2}, 20 \mathrm{mM}$ TEA-Cl, $5 \mathrm{mM} \mathrm{CsCl}, 0.1 \mathrm{mM} \mathrm{CdCl}_{2}$, and $10 \mathrm{mM}$ HEPES and was adjusted to $\mathrm{pH} 7.3$ and $320 \mathrm{mOsm} / \mathrm{L}$.

\section{Experimental Design and Statistical Analysis}

Normal distribution of data was checked using Shapiro-Wilk tests. Statistical significance of normally distributed data was tested by unpaired 2-tailed $t$ tests. Non-normally distributed data were tested by Mann-Whitney $U$ tests. A probability of error of $p<0.05$ was considered significant. All results are presented as mean $( \pm \mathrm{SD})$ if not stated otherwise.

\section{Data Availability}

The data that support the findings of this study are available from the corresponding author on reasonable request.

\section{Results}

\section{Patients' Autoantibodies Bind to Dorsal Root Ganglion Neurons and Cerebellar Granule Neurons}

Binding assays of patients' sera on CNTN1-transfected HEK293 cells, DRG neurons, and CGNs showed clear binding of patients' sera or plasma exchange (PE) material, which colocalized with the commercial CNTN1 antibody signal (Figure 1, A-L and Figure 2, A-C).

\section{Cerebellar Granule Neurons and DRG Neurons Show Decreased CNTN1 Expression After Incubation With Anti-CNTN1 Autoantibody Positive Sera}

Incubation of CGNs and DRG neurons with patient sera for 2 days reduced the CNTN1 signal, whereas incubation with 


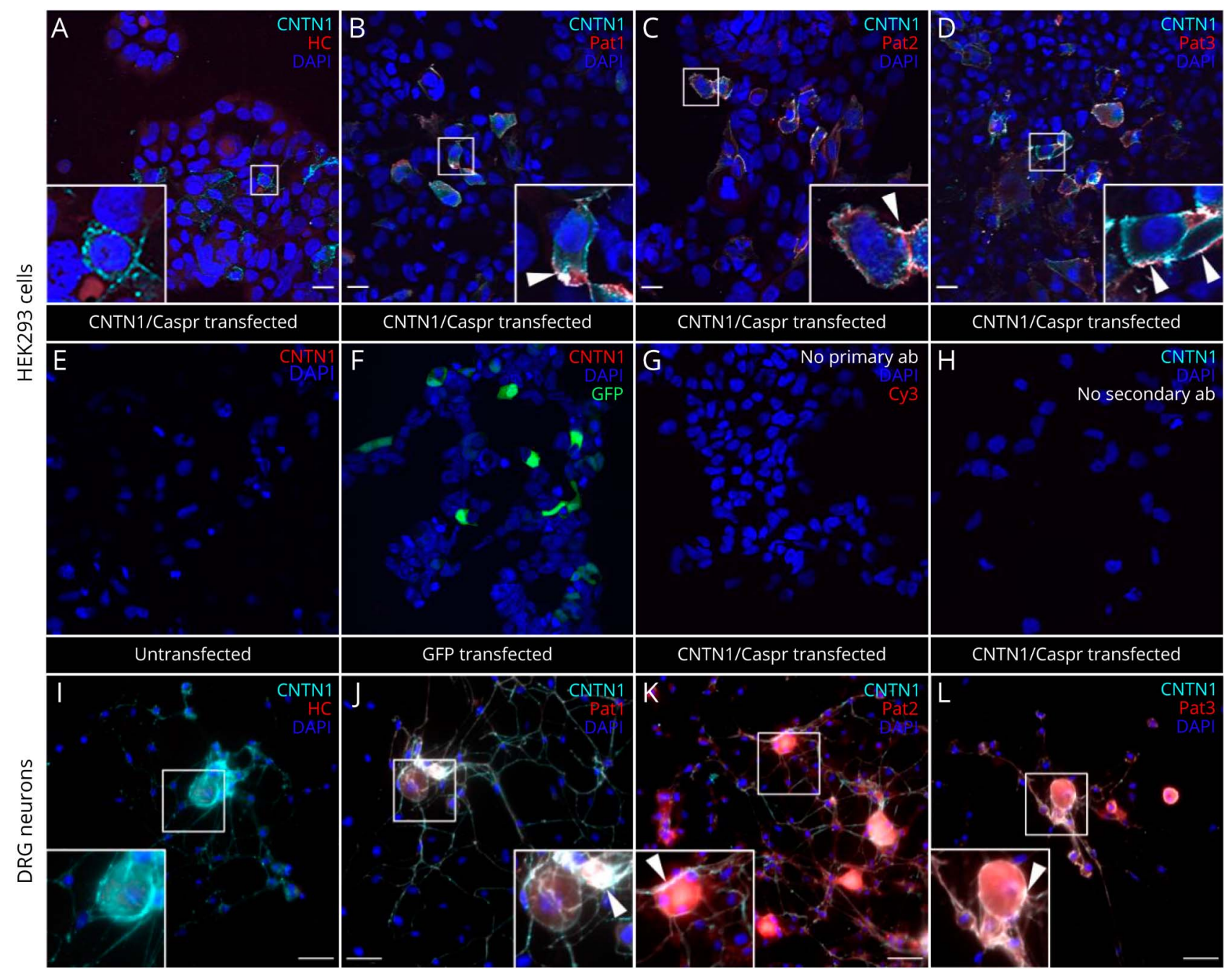

(A-D) Immunofluorescence of CNTN1-transfected HEK293 cells shows binding of serum of patient (pat) 1 (B, red), PE material of pat2 (C, red), and serum of pat3 (D, red), whereas no binding was detectable for serum of a HC (A, red). Scale bars: $20 \mu \mathrm{m}$. (E-H) Control stainings of HEK293 cells showed no staining of untransfected or GFP-transfected cells (E-F) because of a lack of endogenous CNTN1 expression. GFP (green) demonstrates transfection efficiency. (G) No primary antibody present = negative control 1. $(\mathrm{H})$ No secondary antibody present = negative control 2. (l-L) Similarly, serum of pat1 (l, red), PE material of pat2 (K, red), and serum of pat3 (L, red) showed clear staining at DRG neurons. By contrast, serum of a HC did not lead to immunolabeling of the neurons (I, red). Scale bars: $50 \mu \mathrm{m}$. (A-L) All cells were costained with anti-CNTN1 antibody (cyan). Note the overlay of the targeted CNTN1 by patient autoantibodies and the commercial antibody (white signal, arrowheads in magnifications). DAPI was used to stain cell nuclei (blue). CNTN1 = contactin-1; DAPI = 4',6-diamidino-2-phenylindole; DRG = dorsal root ganglia; GFP = green fluorescent protein; HC = healthy control; HEK293 = human embryonic kidney 293; PE = plasma exchange.

control serum did not (Figure 2E). As patient material was limited and the effect did not differ between CGNs and embryonal DRG neurons, the following experiments were conducted with more robust CGNs alone: Incubation for 4 days showed an almost complete decrease in the CNTN1 expression (Figure 2E). After 2R, fluorescent signals of CNTN1 recurred (Figure 2E). Quantification of CNTN1 expression by Western blot of cell lysates revealed reduced CNTN1 expression of cells treated with serum of pat 1 for 2 days $(21 \% \pm 3 \%)$ and 4 days $(7 \% \pm 0.56 \%)$ compared with the HCs (Figure 3, A and C; http://links.lww.com/ NXI/A585; eTable 1). After 2R, CNTN1 expression increased again to $20 \% \pm 1 \%$. Similarly, expression levels of neurons incubated with serum of pat 3 were reduced after 2 days $(29 \% \pm 5 \%)$ and 4 days $(18 \% \pm 1 \%)$ but were rescued after $2 \mathrm{R}(39 \% \pm 0.26 \%)$ (Figure 3, B and C; http://links. lww.com/NXI/A585; eTable 1).

Cytotoxicity assays did not show any difference of $\mathrm{LDH}$ release of CGNs treated with serum of pat 1 compared with $\mathrm{HC}$ treatment. Treatment with serum of pat3 (mainly IgG4) resulted in increased $\mathrm{LDH}$ release of CGNs (3 days: $44 \% \pm$ $0.68 \%$; $\mathrm{t}=14.11$, $\mathrm{df}=7, p=0.000002,4$ days: $39 \% \pm 1 \% ; p=$ 0.0004 ) compared with a HC (3 days: $20 \% \pm 3 \%, 4$ days: $27 \%$ $\pm 3 \%$ ) after 3 and 4 days of treatment, not after 2 days (Figure 3D, please notice that only measurements of the same time point should be compared as for technical reasons, different time points needed to be run in different assays). No obvious changes in the neurofascin or beta-III-tubulin expression pattern after incubation with serum of pat 1 and pat 3 
Figure 2 Immunofluorescence of CGNs Shows Reduced Expression of CNTN1 After Long-term Incubation With Serum of Anti-CNTN1-Positive Patients
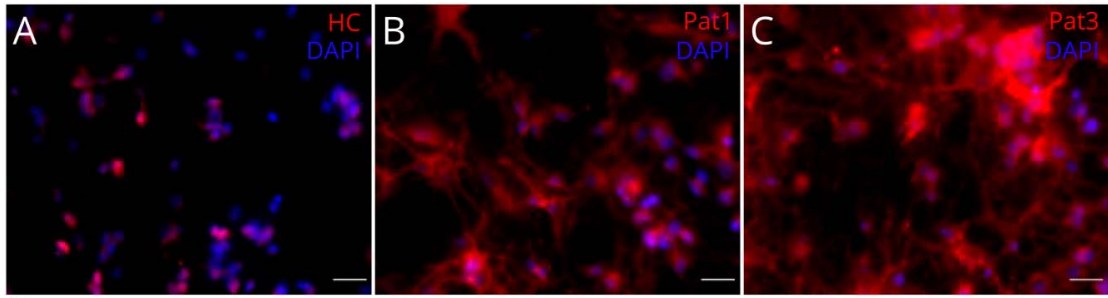

D

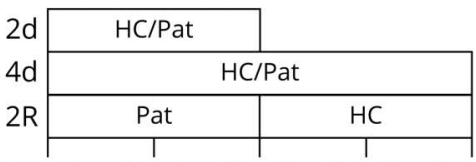

Day 0 Day 1 Day 2 Day 3 Day 4

E

$2 d$

$4 d$

$2 \mathrm{R}$
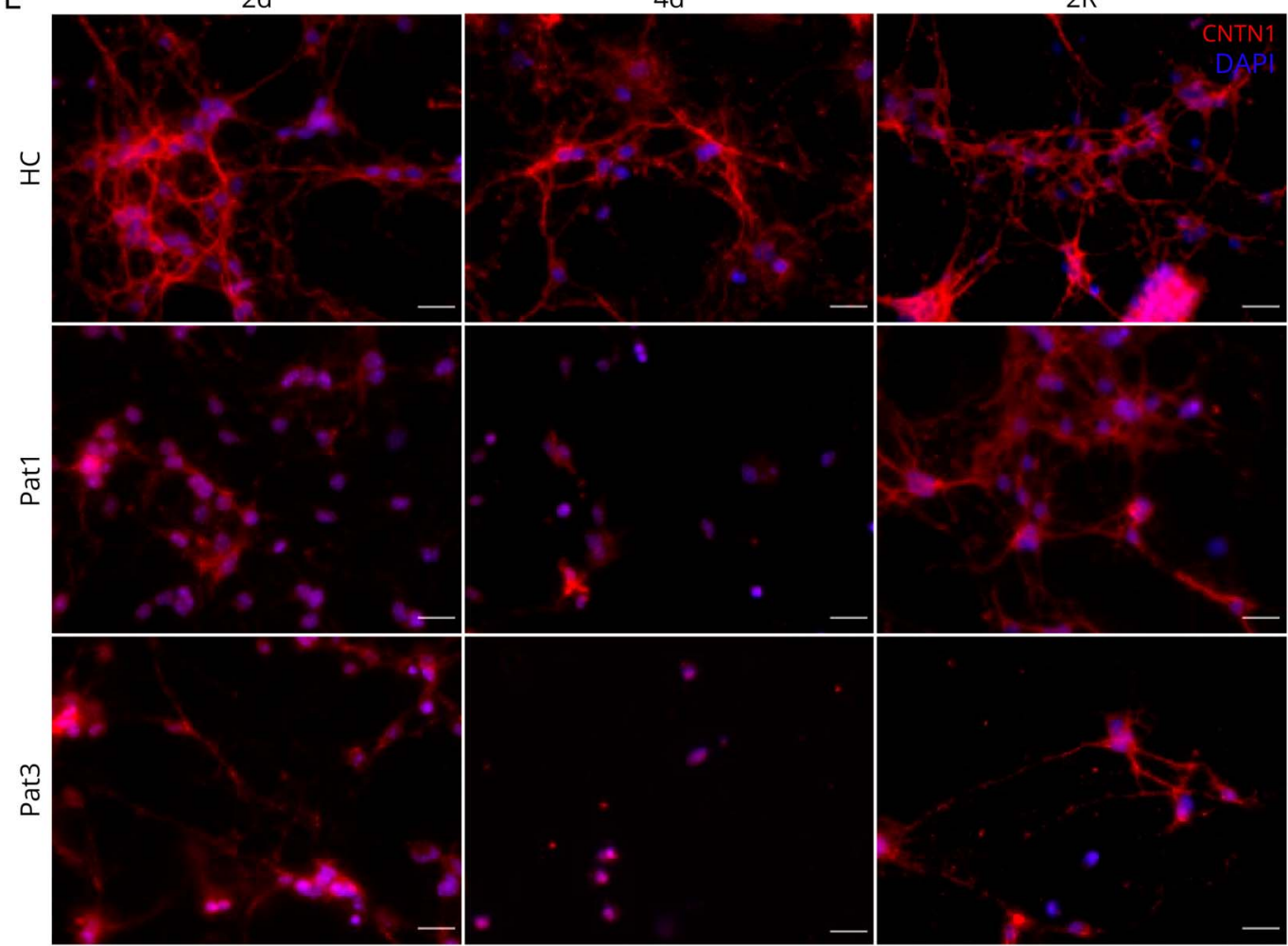

(A-C) Immunofluorescence of cerebellar granule neurons shows binding of sera of patient (pat) 1 (B) and pat3 (C). No specific binding is detectable for serum of a HC (A). DAPI was used for staining cell nuclei (blue). Scale bars refer to $20 \mu \mathrm{m}$. (D) Scheme of the experimental setup. Two to four days after seeding cerebellar granule neurons, cells were incubated for 2 or 4 days with serum of a HC or sera of patients (pat) 1 and 3 . In addition, cells were incubated with serum of pat 1 and pat 3 for 2 days followed by incubation with serum of a HC for 2 days (recovery period, 2R). (E) Representative images of cerebellar granule neurons treated with serum of a HC or serum of pat 1 or pat 3 for specific periods of time ( 2 days, 4 days, and $2 \mathrm{R})$ and stained for CNTN1 (red). Signal of CNTN1 is reduced after 2 and 4 days of incubation with pat sera. The recovery phase of 2 days ( $2 R$ ) leads to increased staining of CNTN1 for both patients. DAPI was used for staining of nuclei (blue). Scale bars: $20 \mu \mathrm{m}$. CGN = cerebellar granular neurons; CNTN1 = contactin-1; DAPI = 4',6-diamidino-2-phenylindole; $\mathrm{HC}=$ healthy control.

for 3 days compared with cells incubated with serum of a $\mathrm{HC}$ were exhibited (http://links.lww.com/NXI/A585; eFigure 1), excluding unspecific loss of neuronal proteins due to cell death.

\section{CNTN1 Reduction Can Be Prevented by Fab Fragment Generation From the Patient IgG}

Reduction of the CNTN1 level after incubation with patient anti-CNTN1 autoantibodies might be due to protein cross- linking by IgG subclasses 1-3. Therefore, Fab fragments unable to crosslink proteins were generated from IgG of patients 1 and 3 and a seronegative control IgG. Reduced CNTN1 expression on DRG neurons was again observed after incubation with serum from patients 1 and 3 for 2 days (Figure 4, A and B). By contrast, the CNTN1 level in DRG neurons was indistinguishable between incubations with seronegative control Fab or Fab fragments from patients 1 and 3 while general 
A

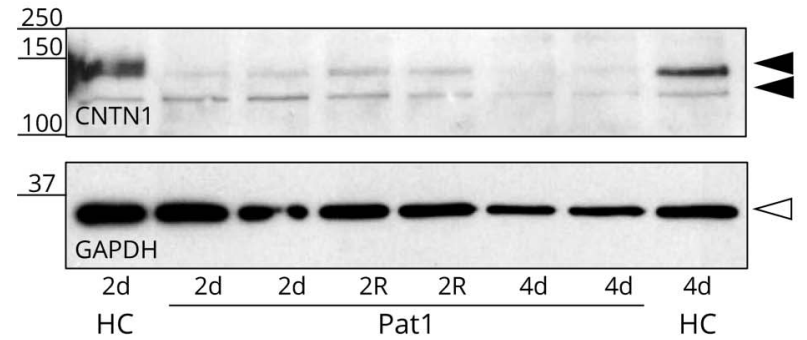

C

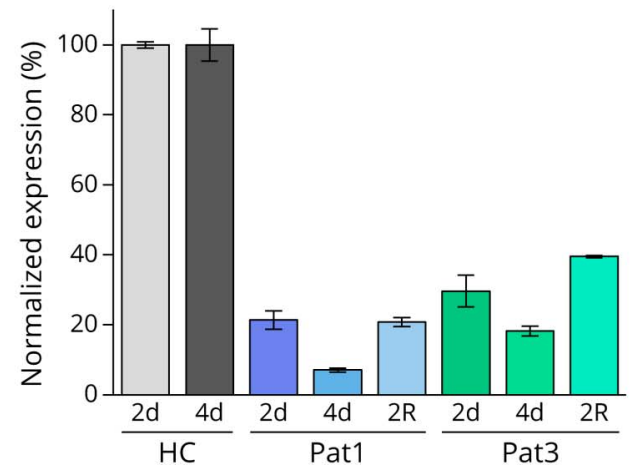

B 250

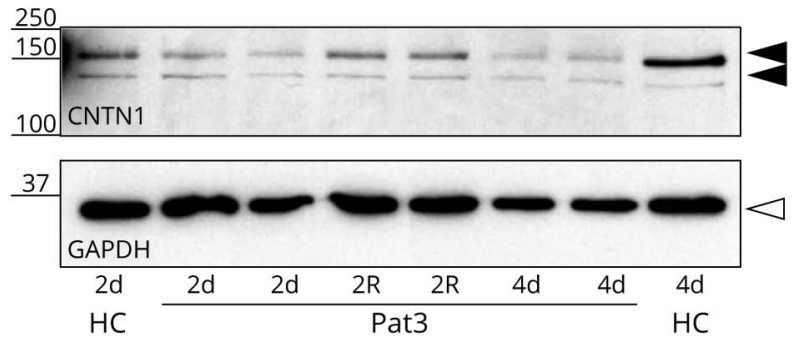

D

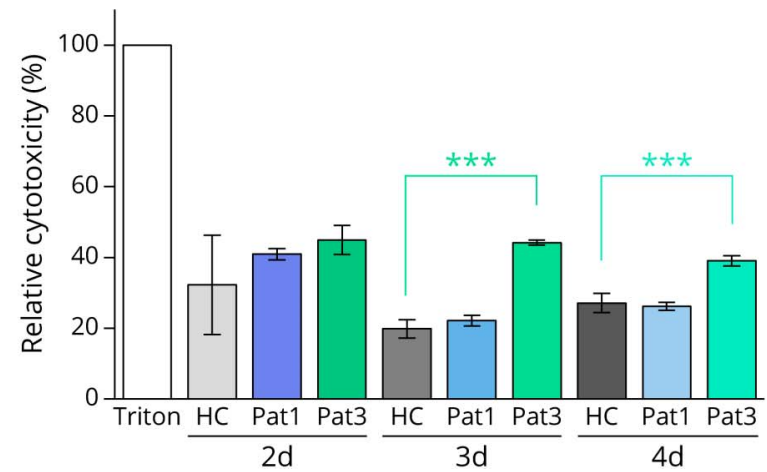

(A-B) Representative Western blots of CNTN1 expression after incubation of cerebellar granule neuron lysates with serum of a HC or serum of pat1 (A) or pat3 (B) for 2 days, 4 days, or 2R. The 2 CNTN1 isoforms with appropriate molecular weights of around 140 kDa were stained with anti-CNTN1 (black arrowheads). GAPDH (37 kDa) was used as a control protein (white arrowheads). (C) Quantification of CNTN1 expression. Expression was normalized to GAPDH, and expression of neurons treated with serum of a HC for 2 and 4 days was set to $100 \%$. Note that because of the limited sample size of 2 samples per condition, statistical analysis was not performed. (D) Relative cytotoxicity of serum of pat1, pat3, or HC to cerebellar neurons. Triton X-100 was used as high control and set to $100 \%$. A cytotoxic effect of pat3 serum

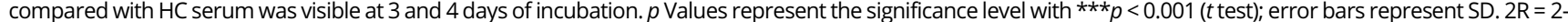
day recovery phase; CGN = cerebellar granular neurons; CNTN1 = contactin-1; GAPDH = Glyceraldehyde 3-phosphate dehydrogenase; HC = healthy control.

binding of Fab fragments to DRG neurons was demonstrated (Figure 4, C and D). Generation of $F\left(a b^{\prime}\right)_{2}$ fragments from a seronegative control IgG and IgG from patient 3 again exhibited slightly reduced CNTN1 expression after incubation with pat3 $\left.\mathrm{F}(\mathrm{ab})_{2}\right)_{2}$ in comparison with $\left.\mathrm{F}(\mathrm{ab})_{2}\right)_{2}$ from a control (eAppendix 1, links.lww.com/NXI/A536; http://links.lww. com/NXI/A585; eFigure 1).

\section{Decreased Surface but Not Whole-Cell Expression of CNTN1 After Incubation With Anti-CNTN1 IgG3 Positive Serum}

CNTN1 immunocytochemical staining of CNTN1-transfected HEK293 cells (Figure 5) did not show any obvious differences of the CNTN1 fluorescence signal for cells treated with a $\mathrm{HC}$ or pat3 (with IgG4>>IgG2 anti-CNTN1) for 2 or 4 days. Similarly, there was no alteration of the signal for cells treated with serum of pat3 after a 2R. By contrast, signal of CNTN1 was clearly reduced after incubation with serum of pat 1 with mainly IgG3 autoantibodies for 2 and 4 days. However, after 2R, CNTN1 signal increased.

To discriminate between surface and whole-cell protein, biotinylation of surface proteins was used in transfected HEK293 cells. Whole-cell fractions from transfected HEK293 cells treated for the 3 time periods were analyzed but did not show any differences between the differently treated groups ( 2 days pat1: $75 \% \pm 14 \%$ or pat $3: 98 \% \pm 14 \%$, HC: $100 \% \pm 11 \%$; 4 days pat 1 :
$102 \% \pm 15 \%$, pat3: $90 \% \pm 23 \%$, HC: $100 \% \pm 8 \%$ ) (Figure 6, A-C; http://links.lww.com/NXI/A585; eTable 1). Similarly, normalized CNTN1 expression was not different in whole-cell lysates after a recovery phase (2R pat $1: 98 \% \pm 25 \%$, pat $3: 71 \% \pm$ $13 \%)$. By contrast, analysis of the CNTN1 surface expression revealed clear differences between pat 1 and pat 3 autoantibodies, which were in line with the observations from the immunocytochemical stainings (Figure 6, D-F). Normalized CNTN1 surface expression of cells incubated for 2 days with serum of pat1 with mainly IgG3 autoantibodies was significantly reduced $(66 \% \pm 11 \% ; p=0.049)$ compared with CNTN1 surface expression of cells treated with serum of a HC for 2 days $(100 \% \pm$ $12 \%)$. This reduction was even more prominent after 4 days of treatment (pat1: 64\% $\pm 9 \%$, HC: $100 \% \pm 8 \%$; $p=0.017$ ). By contrast, incubation of HEK293 cells with serum of pat 3 for 2 days $(99 \% \pm 9 \%)$ or 4 days $(92 \% \pm 23 \%)$ did not disclose a reduction of CNTN1 surface expression compared with a HC and compared with the similar analysis in primary CGNs. Similarly, no differences were detected after 2 days of treatment with serum of pat 3 following 2 days of recovery $(80 \% \pm 19 \%)$ (Figure 6, D-F; http://links.lww.com/NXI/A585; eTable 1).

\section{Reduction of CNTN1 in DRG Neurons Does Not Lead to a Decreased Expression of $\mathrm{Na}_{v}$ Channels}

To investigate whether a change in the overall structure of the protein complex of CNTN1 and $\mathrm{Na}_{\mathrm{V}}$ channels might be 


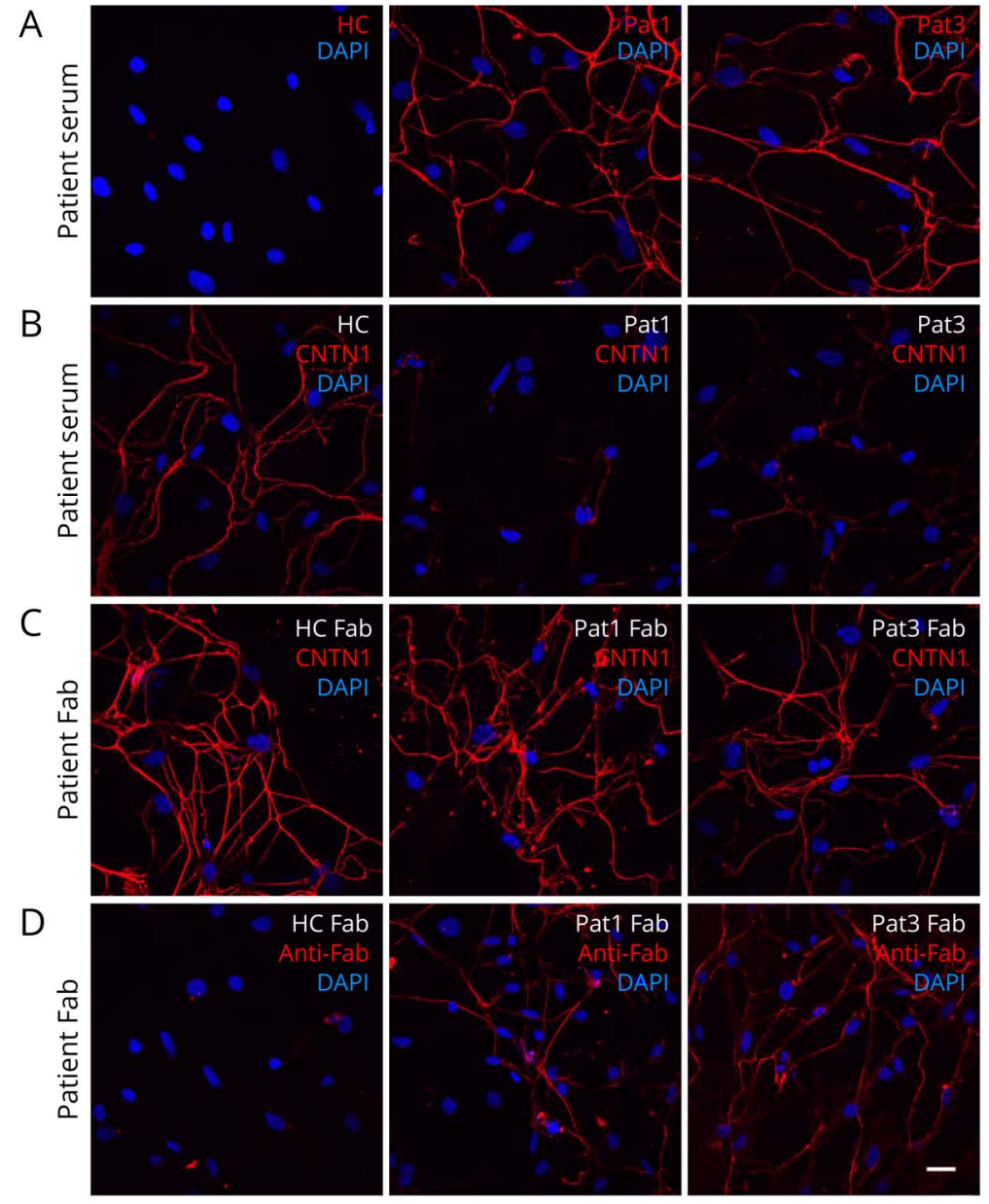

(A, B) DRG neurons treated for 2 days with serum of pat1 and pat3 or a HC. (A) Cells were stained for the binding of the patient IgG (red) to the DRG neurons. (B) After binding of patients' CNTN1 autoantibodies, DRG neurons were controlled for the CNTN1 level. Note the CNTN1 signal reduction after incubation with serum from pat1 (more pronounced) and pat3. (C, D) DRG neurons incubated for 2 days with Fab fragments generated from patient IgGs. (C) The CNTN1 level after Fab fragment ( $\mathrm{HC}$, pat1, and pat3) binding is shown. (D) The binding of Fab from pat 1 and 3 was proven by binding of anti-Fab Cy3 secondary antibodies. The nuclei are always marked by DAPI binding (blue). Scale bar refers to $20 \mu \mathrm{m}$. CNTN1 = contactin-1; DAPI = 4',6-diamidino-2-phenylindole; DRG = dorsal root ganglia; $\mathrm{HC}=$ healthy control.

caused by anti-CNTN1 autoantibody binding, SIM was performed. The following experiments were performed on adult DRG neurons to exclude effects of variant expression levels of sodium channels at embryonal stages. Selected axonal regions from SIM images of adult DRG neurons treated with either $\mathrm{HC}$ or pat 1 serum for 72 hours with costained CNTN1 and $\mathrm{Na}_{\mathrm{V}}$ are shown in Figure 7A. Intensity profiles along the selected regions showed markedly overlapping signals of CNTN1 and pan- $\mathrm{Na}_{\mathrm{V}}$ in neurons treated with serum of a $\mathrm{HC}$ (Figure $7 \mathrm{~B}$, left panel). By contrast, the intensities did not overlap as strongly after treatment with patient serum (Figure 7B, right panel). Colocalization analysis of CNTN1 and pan-Na $\mathrm{V}_{\mathrm{V}}$ signals (Figure 7C) showed a Pearson correlation coefficient of $0.4 \pm$ $0.09(\mathrm{n}=44)$ in DRG neurons incubated with serum of HCs for 72 hours. Treatment with patient material led to lower Pearson correlation coefficients compared with the control group (pat1: $0.35 \pm 0.08, p=0.0096$; pat2: $0.34 \pm 0.08, p=0.017$; pat3: $0.34 \pm$ $0.06, p=0.003$ ). Signal intensity measurements (Figure 7D) revealed a significant reduction of CNTN1 as already detected in CGNs, DRG neurons, and transfected HEK293 cells. Treatment with serum of pat1 with predominantly IgG3 autoantibodies showed the most pronounced reduction in signal density compared with HCs (mean signal density pat1: $9.26 \times 10^{5} \pm 1.5 \times$
$10^{5}$ a.u. $/ \mu \mathrm{m}^{2}, \mathrm{n}=16$; HC: $1.43 \times 10^{6} \pm 4.7 \times 10^{5}$ a.u. $/ \mu \mathrm{m}^{2}, \mathrm{n}=$ 43; $p=0.0008)$. Incubation with PE material of pat 2 or serum of pat3 led to a similar decrease in signal density of CNTN1 (mean signal density pat2: $1.09 \times 10^{6} \pm 3.18 \times 10^{5}$ a.u. $/ \mu \mathrm{m}^{2}, p=0.0086$; pat3: $1.04 \times 10^{6} \pm 3.14 \times 10^{5}$ a.u. $\left./ \mu \mathrm{m}^{2}, p=0.0139\right)$. By contrast, signal densities of pan- $\mathrm{Na}_{\mathrm{V}}$ did not change after incubation with patient serum compared with HCs (mean signal density pat1: $1.72 \times 10^{6} \pm 1.23 \times 10^{6}$ a.u. $/ \mu \mathrm{m}^{2}, p=0.9$; pat2: $1.43 \times 10^{6} \pm 7.87$ $\times 10^{5}$ a.u. $/ \mu \mathrm{m}^{2}, p=0.5$; pat3: $1.68 \times 10^{6} \pm 1.07 \times 10^{6}, p=0.9$; HC: $1.61 \times 10^{6} \pm 8.38 \times 10^{5}$ a.u. $\left./ \mu \mathrm{m}^{2}, \mathrm{n}=44\right)$.

\section{Effect of Anti-CNTN1 Autoantibodies on Sodium Currents of DRG}

Whole-cell recordings from DRG neurons pretreated with patient sera for various time points were characterized for voltage-gated sodium channels (Figure 8A). Typical inward sodium currents were observed using a voltage step protocol from -80 to $+60 \mathrm{mV}$ (Figure $8 \mathrm{~B}$ ). Sodium peak currents showed pronounced decrease in the amplitudes at different voltage steps when neurons were incubated with patients' material compared with those treated with $\mathrm{HC}$ sera (Figure 8B). This effect was most prominent after long-term incubation. Comparison of peak current densities at $-40 \mathrm{mV}$ 

Autoantibodies

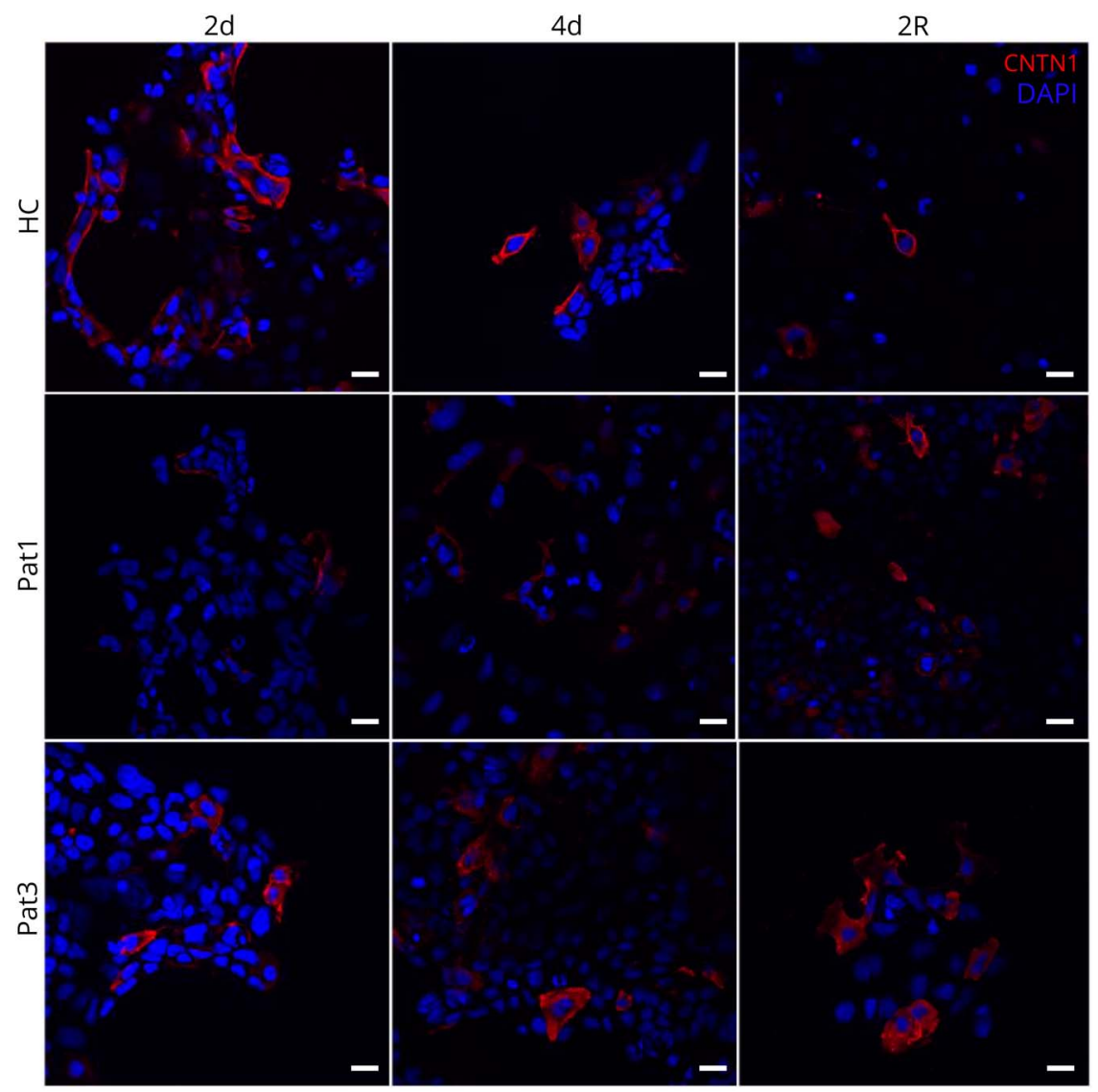

Representative images of the appropriate conditions ( 2 days, 4 days, and 2R) shown for cells incubated with $\mathrm{HC}$ serum $(1: 500)$, pat1 $(1: 500$, red) or pat3 $(1: 500$, red). Note the reduced signal of CNTN1 in cells incubated with serum of pat1 for 2 and 4 days. DAPI was used to mark the nucleus (blue). Scale bar refers to $20 \mu \mathrm{m} .2 \mathrm{R}=2$-day recovery phase; CNTN1 = contactin-1; DAPI = 4',6diamidino-2-phenylindole; $\mathrm{HC}=$ healthy control HEK293 = human embryonic kidney 293.

(Figure 8C) revealed no differences in cells treated with patients' material for short incubation times compared with pooled current densities of 3 HCs. Long-term incubation ( 72 hours) of DRG neurons, however, led to decrease in sodium current densities when treated with serum of pat1 $(200 \pm 2 \mathrm{pA} / \mathrm{pF} ; p=$ $0.016)$ or pat $3(185 \pm 18 \mathrm{pA} / \mathrm{pF} ; p=0.007)$ compared with the control group $(262 \pm 19 \mathrm{pA} / \mathrm{pF}, \mathrm{n}=32$, Figure $8 \mathrm{C}$, http://links. lww.com/NXI/A585; eTable 2). Similarly, current-voltage relationships (Figure $8 \mathrm{D}$ ) revealed reduced current densities at voltages of -60 to $0 \mathrm{mV}$ of cells treated with serum of pat 1 or pat 3 compared with the control group at time point of 72 hours, whereas no significant changes were observed after 1-hour incubation. Differentiation of DRG neurons by size as previously performed ${ }^{25}$ revealed that medium-large diameter cells $(>15 \mathrm{pF})$ are more affected by the treatment with patients' material than small neurons $(<15 \mathrm{pF}$; data not shown). Here, incubation with serum of pat 3 for 72 hours exhibited a reduction of the sodium current density compared with the control group (pat3: $163 \pm 18$ $\mathrm{pA} / \mathrm{pF}, \mathrm{n}=14 ; \mathrm{HC}: 215 \pm 15 \mathrm{pA} / \mathrm{pF}, \mathrm{n}=17 ; p=0.044)$.

\section{Discussion}

We demonstrate decreased surface expression of CNTN1 on neurons after incubation with anti-CNTN1-positive sera and diminished $\mathrm{Na}_{V}$ current densities albeit no loss of $\mathrm{Na}_{V}$ channel expression. These effects were more pronounced in a patient with a predominance of IgG3 compared with a patient with mostly IgG4, whereas mild cytotoxic effects were found in incubation experiments with serum of a patient with mainly IgG4 anti-CNTN1 autoantibodies.

Our data argue for a direct effect of anti-CNTN1 autoantibodies on neuronal CNTN1 and support the idea of DRG as a second site of attack besides the paranodes in patients with anti-CNTN1 autoantibodies.

Recent studies focusing on the clinical symptoms of antiCNTN1 seropositive patients reported sensory ataxia as one of the disabling symptoms, ${ }^{12,20,26,27}$ raising the suspicion that the paranodes may not be the only site of pathogenicity. DRG are easily accessible by autoantibodies because of the lack of a sufficient neurovascular barrier, ${ }^{28}$ and our data give evidence of a direct effect of anti-CNTN1 autoantibodies on DRG, thus supporting the notion of DRG as another site of pathogenicity. Cerebellar binding was discussed as a potential correlate of tremor in patients with paranodal autoantibodies. Although intrathecal synthesis of antiparanodal autoantibodies has not been shown yet, elevated protein levels in the CSF are commonly seen 
Figure 6 Quantitative Analysis of CNTN1 Expression Levels Shows Reduced CNTN1 Surface Expression After Long-term Exposure to Mainly IgG3 Anti-CNTN1 Autoantibodies in Transfected HEK293 Cells

A. Whole-cell expression.
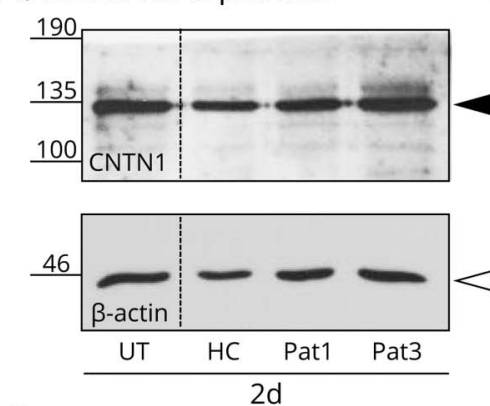

C

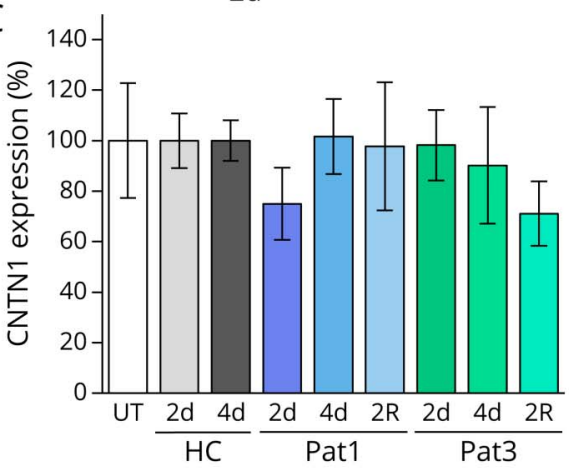

D. Surface expression.

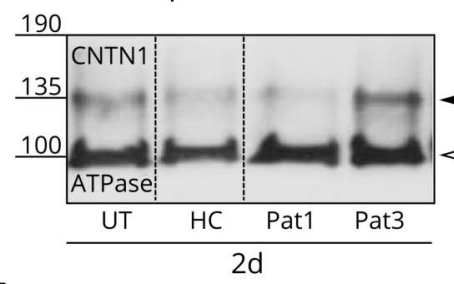

E

$\mathrm{F}$

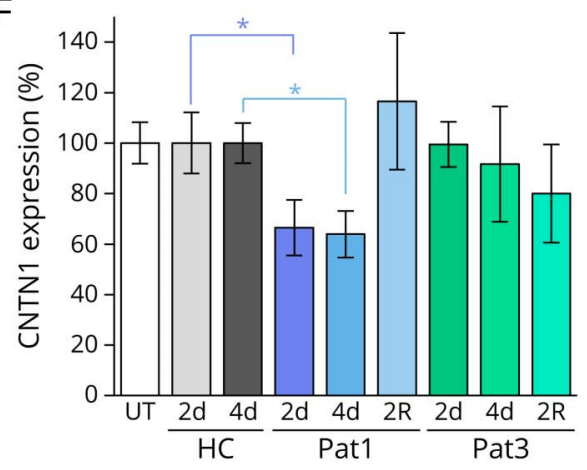

B
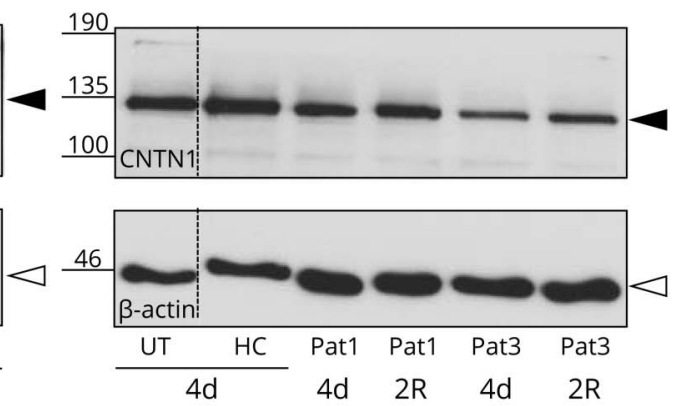

$4 d$

$4 d \quad 2 R \quad 4 d \quad 2 R$

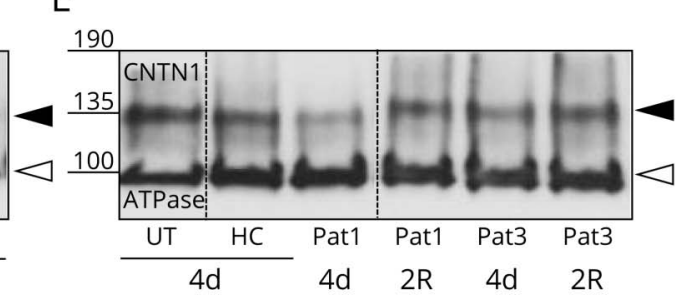
(A) Representative Western blots of the whole-cell
CNTN1 expression after 2 days of the incubation
period with pat sera or a HC. Staining was per-
formed with CNTN1 antibody ( $140 \mathrm{kD}$, black ar-
rowheads) and $\beta$-actin as control protein ( $46 \mathrm{kD}$
marked by white arrowheads). (B) Whole-cell
fractions of condition 4 days of incubation and $2 \mathrm{R}$.
Same HC, as well as pat1 and pat3 serum were
used. Dotted lines in (A, B) indicate that the lane
was cut but from the same Western blot. (C)
Quantification of the whole-cell CNTN1 expres-
sion. CNTN1 expression was normalized to $\beta$-ac-
tin, and the expression with HC serum at 2 days, 4
days, and 2 R was always set to $100 \%$. (D, E) Same
as in (A, B), but surface fractions were stained.
ATPase was used as control protein for the cel-
lular membrane (100 kD, white arrowheads).
Note the reduction of CNTN1 protein in fractions
incubated with pat1 serum at $2-$ and 4 -day pres-
ence of the autoantibodies. Dotted lines in (D, E)
label cut lanes from the same Western blot. (F)
Quantification of the surface CNTN1 protein
normalized to ATPase levels. Again, the HC incu-
bations at 2 days, 4 days, and $2 R$ were set to $100 \%$
and compared with patient serum presence.
Value of significance, ${ }^{\star} p<0.05$. $2 R=2$-day re-
covery phase; CNTN1 = contactin-1; HC = healthy
control; HEK293 = human embryonic kidney 293 .

in anti-CNTN1-positive patients, ${ }^{12,13,27}$ most probably caused by a breakdown of the blood-brain barrier. Thus, a pathogenic effect of anti-CNTN1 autoantibodies on CGNs in vivo remains questionable and needs to be further investigated. ${ }^{13,29-31}$

Anti-CNTN1 autoantibodies are known to mostly belong to the IgG4 subclass ${ }^{1,12,13}$ that does not induce internalization of surface proteins. ${ }^{32}$ Pathogenicity of IgG4 autoantibodies is supposed to be mediated by direct blocking of protein-protein interactions. $^{32}$ Our biotinylation experiments in transfected HEK293 cells show that binding of patients' anti-CNTN1 autoantibodies decreased surface CNTN1 expression, whereas whole-cell CNTN1 expression was rather unaffected. Incubation with Fab fragments of patients' autoantibodies that bind to CNTN1 but do not induce cross-linking did not lead to a reduction of CNTN1. Hence, internalization of surface CNTN1 and subsequent protein degradation are suggested to contribute to the observed decrease of CNTN1, most probably as a consequence of protein cross-linking. Although surfaceexpressed CNTN1 was also reduced in the presence of antiCNTN1 autoantibodies from a patient with mainly IgG4, a significant decrease of surface CNTN1 was only demonstrated 

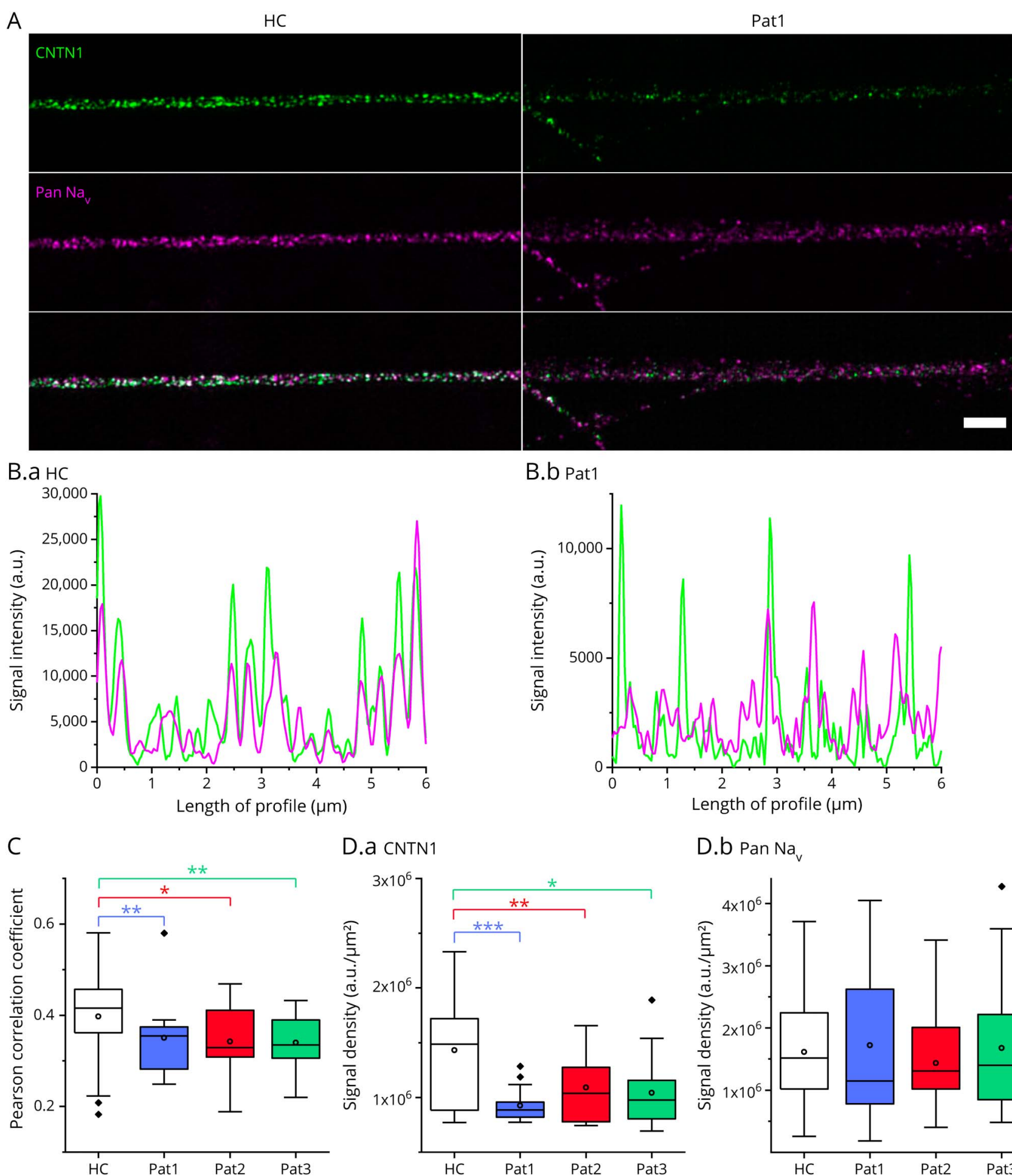

D.a CNTN1

D.b Pan $\mathrm{Na}_{\mathrm{v}}$
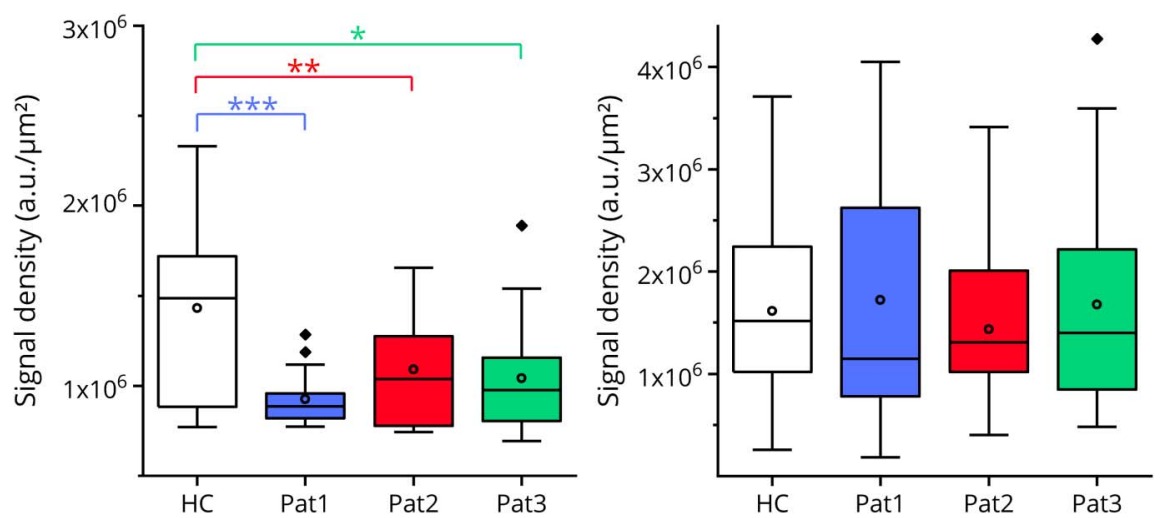

(A) SIM recordings on adult DRG neurons immunostained for CNTN1 and pan-Nav and incubated with single pat sera or HC sera (controls = pooled) for 72 hours. Single stretch along the axon taken from a large field of view recording. Scale bar: $2 \mu \mathrm{m}$. (B) Exemplary profile plots along $6 \mu \mathrm{m}$ of axon (taken from [A]) for showing the level of coincidence of CNTN1 and pan-Nav signals in representative SIM recordings after incubation with serum of HC (B.a) or pat1 (B.b). Note the different $y$-axis scale. (C) Colocalization analysis of CNTN1 and pan-NaV depicting Pearson correlation coefficients. (D) Analysis of signal density (sum intensity/summed area in $\mu \mathrm{m}^{2}$ ) of CNTN1 (D.a) and pan-Nav (D.b) over CNTN1 ROIs. Values of significance, ${ }^{*} p<0.05, * * p<0.01$, and $* * * p<0.001$. CNTN1 $=$ contactin-1; DRG = dorsal root ganglia; $\mathrm{HC}=$ healthy control; $\mathrm{ROI}=$ region of interest; $\mathrm{SIM}$ = structured illumination microscopy.

for the patient with IgG3 autoantibodies. Incubation experiments with CGNs, however, revealed a reduction of CNTN1 also after incubation with serum of a patient with IgG4 predominance, arguing that additional processes such as functional block might also underlie changes in the CNTN1 level. The observed more pronounced effect of anti-CNTN1 
Figure 8 Reduced Sodium Currents for DRG Neurons After Long-term Incubation With Serum of Anti-CNTN1-Positive Patients
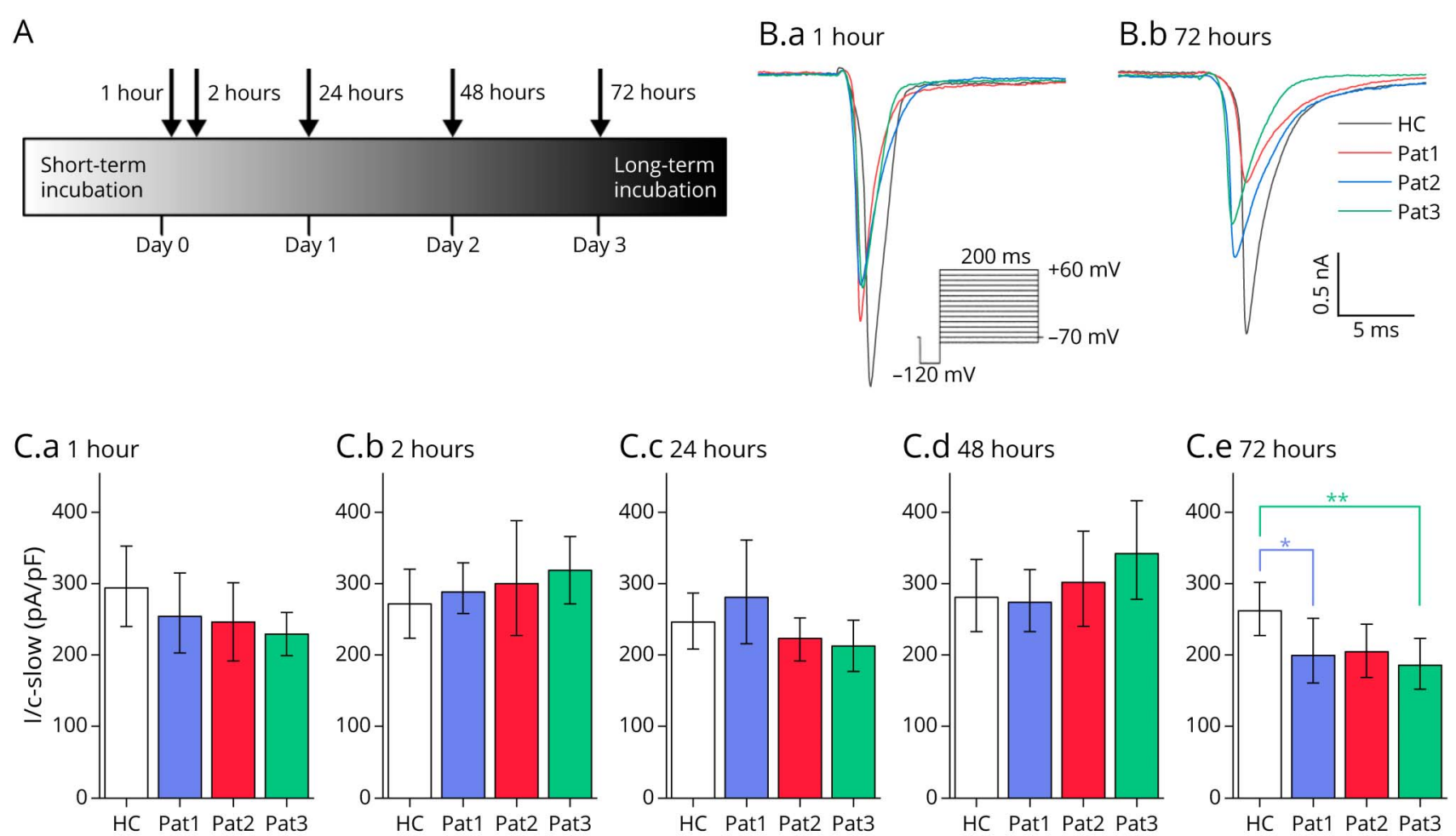

C.e 72 hours

D.a 1 hour

D.b 72 hours
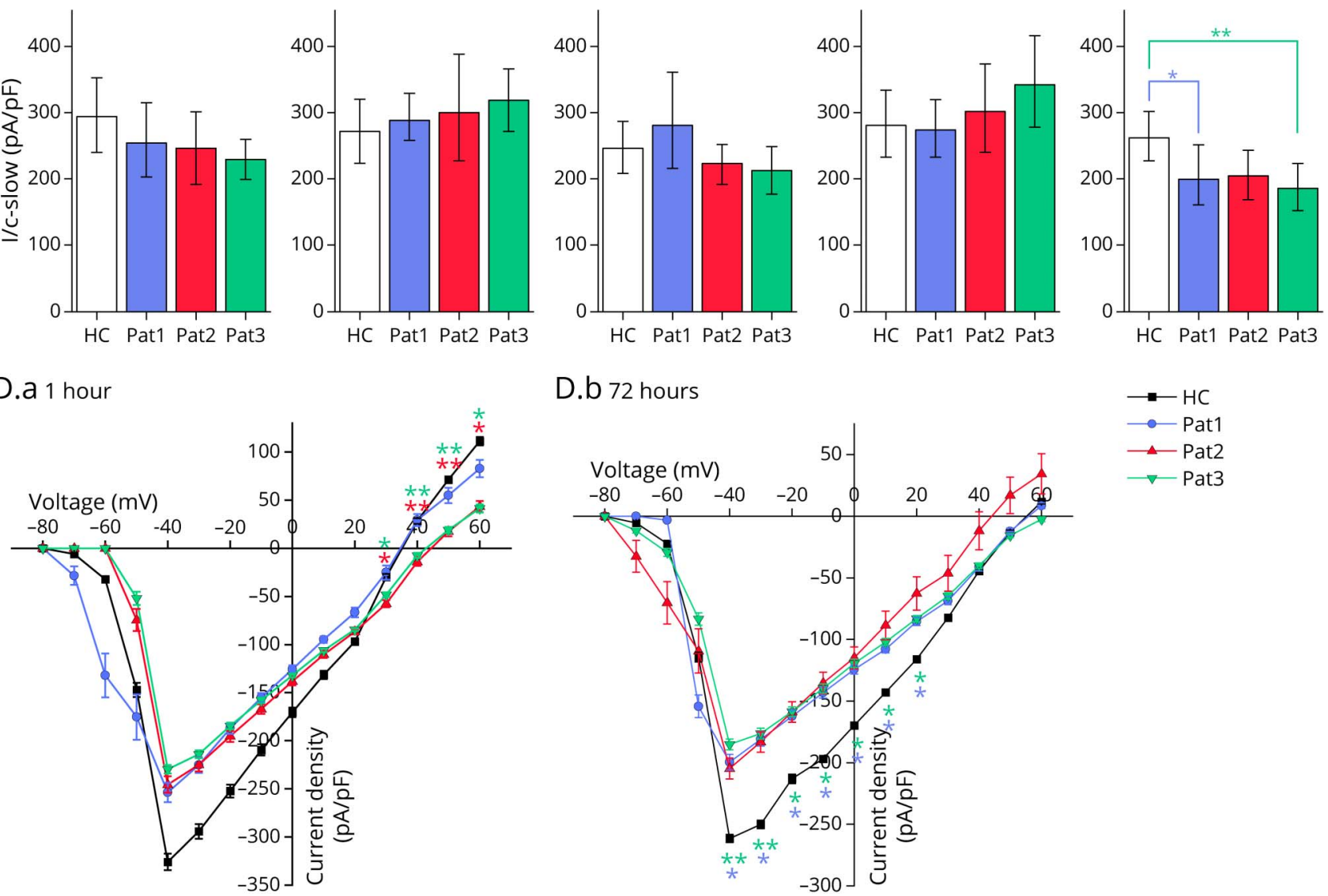

(A) Scheme of short-term and long-term incubation experiments. DRG neurons were incubated with serum of pat1, PE material of pat2, or serum of pat3 for specific periods of time $(1,2,24,48$, and 72 hours). (B) Representative sodium current traces at -40 mV for DRG neurons treated with patients' serum or PE sample or serum of a HC for 1 (B.a) or 72 hours (B.b). The voltage step protocol consisted of a prepulse potential of $-120 \mathrm{mV}$ and of $200 \mathrm{~ms}$ steps ranging from -80 to +60 $\mathrm{mV}$ in $10 \mathrm{mV}$ increments at a holding potential of $-70 \mathrm{mV}$. (C) Average peak current densities for sodium channels at $-40 \mathrm{mV}$ after incubation with serum of a $\mathrm{HC}$, serum of pat1, PE material of pat2, or serum of pat3 for specific periods of time. Short-term incubation (1 hour, C.a; 2 hours, C.b; 24 hours, C.c; 48 hours, C.d) showed no effects on sodium currents, whereas incubation with serum of pat1 and pat 3 for 72 hours showed a significant reduction of sodium current density (C.e). Error bars represent standard errors of the mean (SEM). (D) Current-voltage relationships of sodium current densities from DRG neurons treated with serum of a HC, serum of pat1, PE material of pat2, or serum of pat3 for 1 hour (D.a) or 72 hours (D.b). $p$ Value represents the significance level with * $p<0.05$ and ** $p<0.01$ (Mann-Whitney U test); error bars represent SD. CNTN1 = contactin-1; DRG = dorsal root ganglia; HC = healthy control; PE = plasma exchange.

autoantibodies on CNTN1 expression in primary neurons compared with the overexpression in HEK293 cells might be due to continuous CNTN1 biosynthesis and protein delivery to the cell membrane by the HEK293 cells. Thus, the smaller effect of the serum of patient 3 may not be detectable in the experiments with HEK293 cells but only in incubation experiments with primary neurons. Accordingly, decreased sodium currents were detectable after incubation with both patients' sera even in the same timeframe as decreased surface expression because patch-clamp recordings were also performed in primary neurons. As IgG4 autoantibodies do not induce cross-linking, loss of surface CNTN1 expression may be 
caused by protein cross-linking by the presence of small amounts of IgG1-3 autoantibodies or by protein degradation induced by autoantibody binding. The hypothesis of an in vitro effect of IgG1-3 is supported by a previous study using serum of the same patients: Complement deposition was induced by serum of the patient with a predominance of IgG4, although IgG4 is known not to bind complement and was considered the effect of small amounts of IgG1-3 that were also detectable. ${ }^{21}$ Further evidence that protein cross-linking is one player in the pathology of CNTN1 autoantibodies and underlies the observed CNTN1 reduction comes from Fab fragment generation of both patient samples. Fab fragments, possibly still able to cause functional blocking, prevented CNTN1 reduction, whereas CNTN1 expression was slightly diminished after binding of $\mathrm{F}\left(\mathrm{ab}^{\prime}\right)_{2}$ fragments. Thus, effects of nondominant complement-activating IgG subclasses may be taken into account when developing therapeutic strategies for IgG4 autoantibody-mediated diseases. Indeed, internalization of surface proteins has recently been demonstrated in several other diseases with IgG4 autoantibodies such as anti-Caspr2-, anti-IgLON5-, and anti-DPPX-mediated disease and was also suggested to be induced by small amounts of other IgG subclasses. ${ }^{33-36}$ However, a conclusion on the effect of different IgG subclasses would require experiments with purified subclass-specific autoantibodies, and differences between the sera may also be explained by other properties of autoantibodies such as affinity or epitopes. The reduction of CNTN1 surface expression was concomitant to the decrease of sodium currents and followed the same timeline with a clear effect after 72 hours. This supports the notion that loss of CNTN1 leads to altered sodium channel activity rather than blocking of sodium channels by autoantibody binding that would most probably lead to an immediate effect.

Although former studies focused on axoglial detachment caused by antiparanodal autoantibodies, we give the first evidence of a direct effect of anti-CNTN1 autoantibody binding on ion channel function of neighboring $\mathrm{Na}_{V}$ channels. A previous study reported increased peak currents and current density in cells cotransfected with CNTN1 and $\mathrm{Na}_{V} 1.2 \alpha$ and $\beta 1$ subunits compared with $\mathrm{Na}_{\mathrm{V}} 1.2$ alone, ${ }^{18}$ and several studies have shown that CNTN1 binds to the $\beta 1$ subunit of $\mathrm{Na}_{V}$ channels and affects surface trafficking of $\mathrm{Na}_{\mathrm{V}} 1.2$, 1.3, and 1.9. ${ }^{19,37,38}$ Decreased $\mathrm{Na}_{\mathrm{V}}$ density was supposed to underlie the decrease of sodium currents. ${ }^{18}$ Using SIM, we could confirm decreased CNTN1 expression on DRG, but $\mathrm{Na}_{\mathrm{V}}$ levels remained unaffected. As a pan- $\mathrm{Na}$ antibody was used, we could not discriminate between $\mathrm{Na}_{V}$ channel subtypes. In line with that, our patch-clamp recordings on DRG neurons after exposure to CNTN1 autoantibodies encompassed the activity of all $\mathrm{Na}_{\mathrm{V}}$ channels. The overall $\mathrm{Na}^{+}$currents were reduced after long incubation periods ( 72 hours) with the patient's anti-CNTN1 autoantibodies. Chronic autoantibody exposure reflects the in vivo situation in which autoantibodies persist over months. It might be argued that neurons can compensate for internalization of CNTN1 and the subsequent effect on the
$\mathrm{Na}_{V}$ expression level during short-term periods with enhanced protein synthesis and homeostasis. Moreover, we cannot rule out that a decrease in $\mathrm{Na}_{\mathrm{V}}$ density may be mediated at a transcriptional level and therefore may not be evident within 72 hours. The decrease in $\mathrm{Na}_{V}$ currents at this time point argues in favor of a functional effect on $\mathrm{Na}_{V}$ currents by loss of CNTN1. The exact mechanism underlying this effect still needs to be clarified, but sodium channel modulation may be altered indirectly as CNTN1 interacts with the $B 1$ subunit of voltage-gated sodium channels. Mutations of the $B 1$ subunit are linked to several types of channelopathies such as epilepsy or cardiac arrhythmia ${ }^{39}$ emphasizing the relevance of the $B 1$ subunit in cell excitability.

The observed effect on $\mathrm{Na}_{\mathrm{V}}$ currents was restricted to mediumlarge DRG neurons, although $\mathrm{Na}_{\mathrm{V}} 1.2,1.3$, and 1.9 that are known to interact with CNTN1 are predominantly expressed on small DRG neurons. However, binding of patients' sera to DRG neurons of all sizes could be demonstrated, indicating that CNTN1 is equally expressed on DRG neurons. When comparing experimental results with clinical symptoms, sensory ataxia can mostly be attributed to large neurons, and although neuropathic pain was described in some patients, small neuron/fiber dysfunction was not a prominent clinical feature; thus, decreased $\mathrm{Na}_{\mathrm{V}}$ currents may be linked to dysfunction of large sensory neurons manifesting as sensory ataxia. ${ }^{12,20,26}$ Binding to DRG neurons was also observed in immunization models of neuropathy with anti-myelin-associated glycoprotein autoantibodies, ${ }^{40}$ another peripheral neuropathy that is characterized by sensory ataxia and autoantibodies that are mainly supposed to be pathogenic by binding to peripheral nerves, and among other morphologic features also show axoglial detachment. ${ }^{41}$

Our study focused on the effect of anti-CNTN1 autoantibodies on neuronal cell bodies, not on the node of Ranvier. Furthermore, the in vitro system does not fully reflect the situation in vivo because there is a lack of glial and other supportive cells. Nevertheless, it may be worthwhile to address a potential direct effect of anti-CNTN1 antibodies on nodal $\mathrm{Na}_{V}$ channels in future studies. CNTN1 is a paranodal adhesion molecule, but nodal expression of CNTN1, associated with $\mathrm{Na}_{V}$ channels, was observed at a small fraction of normal adult nodes and frequently at remyelinating nodes. ${ }^{18}$ So it might be speculated that CNTN1 may also affect nodal $\mathrm{Na}_{\mathrm{V}}$ channels, especially in conditions of severe disruption of the nodal architecture as described in patients with antiCNTN1 autoantibodies. ${ }^{10,13}$

Recovery of CNTN1 surface expression within 2 days after removal of anti-CNTN1-positive sera and only minor effects in the cytotoxicity assays suggests absence of fundamental neurotoxic effects of sera, which is consistent with internalization as the cause of decreased surface expression and raises hope of recovery of symptoms after autoantibody removal in patients. 
In summary, our study gives first evidence of a direct effect of anti-CNTN1 autoantibodies on $\mathrm{Na}_{\mathrm{V}}$ currents and supports the notion of DRG neurons as a second site of attack beyond the paranodes.

\section{Acknowledgment}

J.G. was supported by the Graduate School for Life Sciences (GSLS) of the Julius-Maximilians-University Würzburg, Germany. The authors thank Barbara Reuter and Dana Wegmann for excellent technical assistance.

\section{Study Funding}

The study was funded by a grant of the Interdisciplinary Center of Clinical Research of the University Hospital Würzburg (IZKF). This work was further granted by the German Research Foundation DO2219/1-1 to K.D. and FOR3004 SYNABS to C.V.

\section{Disclosure}

J. Grüner reports no disclosures relevant to the manuscript. H. Stengel reports no disclosures relevant to the manuscript. C. Werner reports no disclosures relevant to the manuscript.C. Sommer reports personal fees from Algiax, Alnylam, Air Liquide, Akcea, Astellas, Pfizer, Grifols, Takeda, UCB, Novartis, and Sanofi-Aventis, all outside the submitted work. C. Villmann reports no disclosures relevant to the manuscript. K. Doppler reports no disclosures relevant to the manuscript. Go to Neurology.org/NN for full disclosures.

\section{Publication History}

Received by Neurology: Neuroimmunology \& Neuroinflammation November 12, 2020. Accepted in final form May 17, 2021.

\section{Appendix Authors}

\begin{tabular}{|c|c|c|}
\hline Name & Location & Contribution \\
\hline $\begin{array}{l}\text { Julia Grüner, } \\
\text { MSc }\end{array}$ & $\begin{array}{l}\text { University } \\
\text { Hospital of } \\
\text { Würzburg }\end{array}$ & $\begin{array}{l}\text { Acquisition and analysis of data, and } \\
\text { drafting the manuscript and figures }\end{array}$ \\
\hline $\begin{array}{l}\text { Helena Stengel, } \\
\text { MD }\end{array}$ & $\begin{array}{l}\text { University } \\
\text { Hospital of } \\
\text { Würzburg }\end{array}$ & Acquisition and analysis of data \\
\hline $\begin{array}{l}\text { Christian } \\
\text { Werner, PhD }\end{array}$ & $\begin{array}{l}\text { University of } \\
\text { Würzburg }\end{array}$ & Acquisition and analysis of data \\
\hline $\begin{array}{l}\text { Luise } \\
\text { Appeltshauser, } \\
\text { MD, MSc }\end{array}$ & $\begin{array}{l}\text { University } \\
\text { Hospital of } \\
\text { Würzburg }\end{array}$ & Acquisition and analysis of data \\
\hline $\begin{array}{l}\text { Claudia } \\
\text { Sommer, MD }\end{array}$ & $\begin{array}{l}\text { University } \\
\text { Hospital of } \\
\text { Würzburg }\end{array}$ & Conception and design of the study \\
\hline $\begin{array}{l}\text { Carmen } \\
\text { Villmann, PhD }\end{array}$ & $\begin{array}{l}\text { University } \\
\text { Hospital of } \\
\text { Würzburg }\end{array}$ & $\begin{array}{l}\text { Conception and design of the study, } \\
\text { acquisition and analysis of data, and } \\
\text { drafting the manuscript and figures }\end{array}$ \\
\hline $\begin{array}{l}\text { Kathrin } \\
\text { Doppler, MD }\end{array}$ & $\begin{array}{l}\text { University } \\
\text { Hospital of } \\
\text { Würzburg }\end{array}$ & $\begin{array}{l}\text { Conception and design of the study, } \\
\text { acquisition and analysis of data, and } \\
\text { drafting the manuscript and figures }\end{array}$ \\
\hline
\end{tabular}

\section{References}

1. Querol L, Nogales-Gadea G, Rojas-Garcia R, et al. Antibodies to contactin-1 in chronic inflammatory demyelinating polyneuropathy. Ann Neurol. 2013;73(3):370-380.

2. $\mathrm{Ng} \mathrm{JK}$, Malotka J, Kawakami N, et al. Neurofascin as a target for autoantibodies in peripheral neuropathies. Neurology. 2012;79(23):2241-2248.

3. Doppler K, Appeltshauser L, Villmann C, et al. Auto-antibodies to contactinassociated protein 1 (Caspr) in two patients with painful inflammatory neuropathy. Brain. 2016;139(pt 10):2617-2630.

4. Vural A, Doppler K, Meinl E. Autoantibodies against the node of Ranvier in seropositive chronic inflammatory demyelinating polyneuropathy: diagnostic, pathogenic, and therapeutic relevance. Front Immunol. 2018;9:1029.

5. Uncini A, Vallat JM. Autoimmune nodo-paranodopathies of peripheral nerve: the concept is gaining ground. J Neurol Neurosurg Psychiatry. 2018;89(6):627-635.

6. Bindon CI, Hale G, Brüggemann M, Waldmann H. Human monoclonal IgG isotypes differ in complement activating function at the level of $\mathrm{C} 4$ as well as C1q. J Exp Med. 1988;168(1):127-142.

7. Tao MH, Smith RI, Morrison SL. Structural features of human immunoglobulin G that determine isotype-specific differences in complement activation. J Exp Med. 1993;178(2):661-667.

8. van der Zee JS, van Swieten P, Aalberse RC. Inhibition of complement activation by IgG4 antibodies. Clin Exp Immunol. 1986;64(2):415-422.

9. Aalberse RC, Stapel SO, Schuurman J, Rispens T. Immunoglobulin G4: an odd antibody. Clin Exp Allergy. 2009;39(4):469-477.

10. Koike H, Kadoya M, Kaida KI, et al. Paranodal dissection in chronic inflammatory demyelinating polyneuropathy with anti-neurofascin- 155 and anti-contactin-1 antibodies. J Neurol Neurosurg Psychiatry. 2017;88(6):465-473.

11. Manso C, Querol L, Lleixà C, et al. Anti-Neurofascin-155 IgG4 antibodies prevent paranodal complex formation in vivo. J Clin Invest. 2019;129(6):2222-2236.

12. Cortese A, Lombardi R, Briani C, et al. Antibodies to neurofascin, contactin-1, and contactin-associated protein 1 in CIDP: clinical relevance of IgG isotype. Neurol Neuroimmunol Neuroinflamm. 2020;7(1):e639.

13. Doppler K, Appeltshauser L, Wilhelmi K, et al. Destruction of paranodal architecture in inflammatory neuropathy with anti-contactin-1 autoantibodies. J Neurol Neurosurg Psychiatry. 2015;86(7):720-728.

14. Doppler K, Schuster Y, Appeltshauser L, et al. Anti-CNTN1 IgG3 induces acute conduction block and motor deficits in a passive transfer rat model. J Neuroinflammation. 2019;16(1):73.

15. Manso C, Querol L, Mekaouche M, Illa I, Devaux JJ. Contactin-1 IgG4 antibodies cause paranode dismantling and conduction defects. Brain. 2016;139(pt 6): 1700-1712.

16. Tan RPA, Leshchyns'ka I, Sytnyk V. Glycosylphosphatidylinositol-anchored immunoglobulin superfamily cell adhesion molecules and their role in neuronal development and synapse regulation. Front Mol Neurosci. 2017;10:378.

17. Treubert U, Brümmendorf T. Functional cooperation of betal-integrins and members of the Ig superfamily in neurite outgrowth induction. J Neurosci. 1998;18(5): 1795-1805.

18. Kazarinova-Noyes K, Malhotra JD, McEwen DP, et al. Contactin associates with $\mathrm{Na}+$ channels and increases their functional expression. J Neurosci. 2001;21(19): $7517-7525$.

19. Rush AM, Craner MJ, Kageyama T, Dib-Hajj SD, Waxman SG, Ranscht B. Contactin regulates the current density and axonal expression of tetrodotoxin-resistant but not tetrodotoxin-sensitive sodium channels in DRG neurons. Eur J Neurosci. 2005;22(1): $39-49$.

20. Miura Y, Devaux JJ, Fukami Y, et al. Contactin 1 IgG4 associates to chronic inflammatory demyelinating polyneuropathy with sensory ataxia. Brain. 2015; 138(pt 6):1484-1491.

21. Appeltshauser L, Weishaupt A, Sommer C, Doppler K. Complement deposition induced by binding of anti-contactin-1 auto-antibodies is modified by immunoglobulins. Exp Neurol. 2016;287(pt 1):84-90.

22. Atak S, Langlhofer G, Schaefer N, et al. Disturbances of ligand potency and enhanced degradation of the human glycine receptor at affected positions G160 and T162 originally identified in patients suffering from hyperekplexia. Front Mol Neurosci. 2015; 8:79.

23. Ball G, Demmerle J, Kaufmann R, Davis I, Dobbie IM, Schermelleh L. SIMcheck: a toolbox for successful super-resolution structured illumination microscopy. Sci Rep. 2015;5:15915.

24. Schindelin J, Arganda-Carreras I, Frise E, et al. Fiji: an open-source platform for biological-image analysis. Nat Methods. 2012;9(7):676-682.

25. Yudin Y, Lutz B, Tao YX, Rohacs T. Phospholipase C delta4 regulates cold sensitivity in mice. J Physiol. 2016;594(13):3609-3628.

26. Delmont E, Brodovitch A, Kouton L, et al. Antibodies against the node of Ranvier: a real-life evaluation of incidence, clinical features and response to treatment based on a prospective analysis of 1500 sera. J Neurol. 2020;267(12):3664-3672.

27. Dubey D, Honorat JA, Shelly S, et al. Contactin-1 autoimmunity: serologic, neurologic, and pathologic correlates. Neurol Neuroimmunol Neuroinflamm. 2020;7(4):e771.

28. Reinhold AK, Rittner HL. Characteristics of the nerve barrier and the blood dorsal root ganglion barrier in health and disease. Exp Neurol. 2020;327:113244.

29. Querol L, Nogales-Gadea G, Rojas-Garcia R, et al. Neurofascin IgG4 antibodies in CIDP associate with disabling tremor and poor response to IVIg. Neurology. 2014; 82(10):879-886. 
30. Stengel H, Vural A, Brunder AM, et al. Anti-pan-neurofascin IgG3 as a marker of fulminant autoimmune neuropathy. Neurol Neuroimmunol Neuroinflamm. 2019;6(5):e603.

31. Appeltshauser L, Brunder AM, Heinius A, et al. Antiparanodal antibodies and IgG subclasses in acute autoimmune neuropathy. Neurol Neuroimmunol Neuroinflamm. 2020;7(5):e817.

32. Koneczny I. A New classification system for IgG4 autoantibodies. Front Immunol. 2018;9:97.

33. Piepgras J, Höltje M, Michel K, et al. Anti-DPPX encephalitis: pathogenic effects of antibodies on gut and brain neurons. Neurology. 2015;85(10):890-897.

34. Hara M, Ariño H, Petit-Pedrol M, et al. DPPX antibody-associated encephalitis: main syndrome and antibody effects. Neurology. 2017;88(14):1340-1348.

35. Giannoccaro MP, Menassa DA, Jacobson L, et al. Behaviour and neuropathology in mice injected with human contactin-associated protein 2 antibodies. Brain. 2019; 142(7):2000-2012.

36. Sabater L, Planagumà J, Dalmau J, Graus F. Cellular investigations with human antibodies associated with the anti-IgLON5 syndrome. J Neuroinflammation. 2016; $13(1): 226$
37. McEwen DP, Meadows LS, Chen C, Thyagarajan V, Isom LL. Sodium channel betal subunit-mediated modulation of Nav1.2 currents and cell surface density is dependent on interactions with contactin and ankyrin. J Biol Chem. 2004;279(16):16044-16049.

38. Shah BS, Rush AM, Liu S, et al. Contactin associates with sodium channel Nav1.3 in native tissues and increases channel density at the cell surface. J Neurosci. 2004; 24(33):7387-7399.

39. O'Malley HA, Isom LL. Sodium channel beta subunits: emerging targets in channelopathies. Annu Rev Physiol. 2015;77:481-504.

40. Ilyas AA, Gu Y, Dalakas MC, Quarles RH, Bhatt S. Induction of experimental ataxic sensory neuronopathy in cats by immunization with purified SGPG. J Neuroimmunol. 2008;193(1-2):87-93.

41. Kawagashira Y, Koike $\mathrm{H}$, Tomita M, et al. Morphological progression of myelin abnormalities in IgM-monoclonal gammopathy of undetermined significance antimyelin-associated glycoprotein neuropathy. J Neuropathol Exp Neurol. 2010;69(11) 1143-1157. 


\title{
Neurology \\ Neuroimmunology \& Neuroinflammation
}

\author{
Anti-contactin-1 Antibodies Affect Surface Expression and Sodium Currents in Dorsal \\ Root Ganglia \\ Julia Grüner, Helena Stengel, Christian Werner, et al. \\ Neurol Neuroimmunol Neuroinflamm 2021;8; \\ DOI 10.1212/NXI.0000000000001056
}

This information is current as of August 24, 2021

Neurol Neuroimmunol Neuroinflamm is an official journal of the American Academy of Neurology.

Published since April 2014, it is an open-access, online-only, continuous publication journal. Copyright

Copyright (C) 2021 The Author(s). Published by Wolters Kluwer Health, Inc. on behalf of the American

Academy of Neurology.. All rights reserved. Online ISSN: 2332-7812.

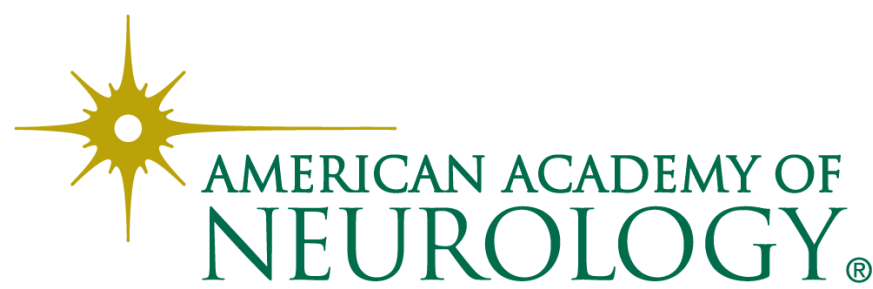




\section{Updated Information \& Services}

References

Subspecialty Collections

Permissions \& Licensing

Reprints including high resolution figures, can be found at: http://nn.neurology.org/content/8/5/e1056.full.html

This article cites 41 articles, 12 of which you can access for free at: http://nn.neurology.org/content/8/5/e1056.full.html\#\#ref-list-1

This article, along with others on similar topics, appears in the following collection(s):

\section{All Immunology}

http://nn.neurology.org//cgi/collection/all_immunology

All Neuromuscular Disease

http://nn.neurology.org//cgi/collection/all_neuromuscular_disease

Autoimmune diseases

http://nn.neurology.org//cgi/collection/autoimmune_diseases

Chronic inflammatory demyelinating polyneuropathy

http://nn.neurology.org//cgi/collection/chronic_inflammatory_demyeli nating_polyneuropathy

Peripheral neuropathy

http://nn.neurology.org//cgi/collection/peripheral_neuropathy

Information about reproducing this article in parts (figures,tables) or in its entirety can be found online at:

http://nn.neurology.org/misc/about.xhtml\#permissions

Information about ordering reprints can be found online:

http://nn.neurology.org/misc/addir.xhtml\#reprintsus

Neurol Neuroimmunol Neuroinflamm is an official journal of the American Academy of Neurology.

Published since April 2014, it is an open-access, online-only, continuous publication journal. Copyright

Copyright $\left({ }^{\circ} 2021\right.$ The Author(s). Published by Wolters Kluwer Health, Inc. on behalf of the American

Academy of Neurology.. All rights reserved. Online ISSN: 2332-7812.

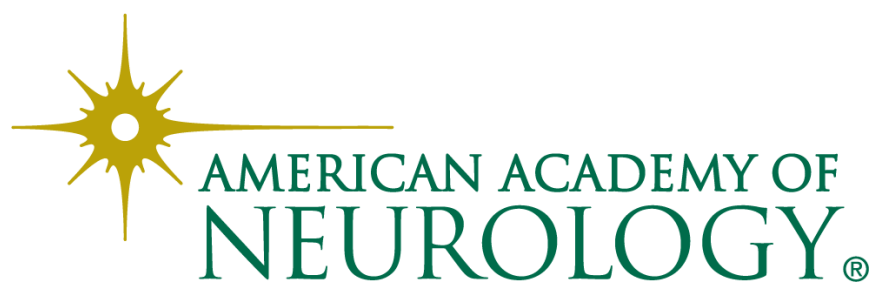

